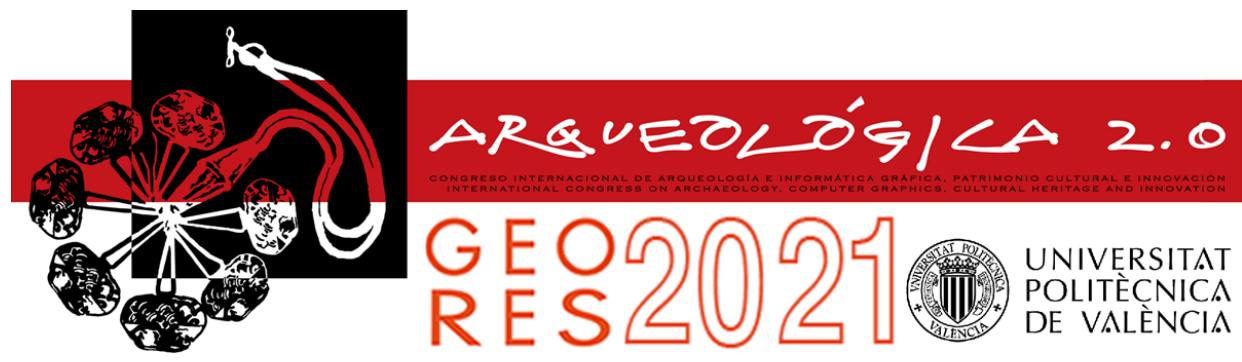

Proceedings of the joint international event $9^{\text {th }}$ ARQUEOLÓGICA

$2.0 \& 3^{\text {rd }}$ GEORES

Valencia (Spain).

26-28 April 2021

\title{
CANOSSA CASTLE: THE IMPORTANCE OF A CRITIC AND AWARE PLAN OF INTERVENTIONS FOR CONSERVATION AND PREVENTION OF CULTURAL HERITAGE
}

\author{
Marco Catellani, Lia Ferrari ${ }^{\star}$, Elena Zanazzi \\ Department of Engineering and Architecture, University of Parma, Viale delle Scienze 181/A, 43124 Parma, Italy. \\ marco.catellani3@studenti.unipr.it; lia.ferrari@unipr.it; elena.zanazzi@unipr.it
}

\begin{abstract}
:
Fortified architecture is a widespread and peculiar typology in Italy as it represents an identifying element for communities and a reference point in the landscape. An imposing system of castles, dating back to the $11^{\text {th }}$ century, characterises the area of Reggio Emilia, in the Emilia Romagna Region. Among these fortifications, Canossa Castle is an important and distinctive fortress. Built on the top of an isolated cliff, a particularly strategic and defensive point, it played a central role in medieval European history. For instance, it was the scene of the well-known reconciliation between Henry IV and Pope Gregory VII, which ended the Investiture Controversy in 1077. The current state of ruins of this fortress is due to both centuries of neglect and to recent incongruent interventions. Therefore, archival research, in-situ inspections and photogrammetric techniques were carried out on the case study of Canossa Castle, in order to analyse the numerous restoration yards that have followed one another on the fortress in the last century. Firstly, the lack of coordination between the different interventions emerged. Furthermore, it has been observed that the principles of restoration have been disregarded several times, with consequent damage to the archaeological remains. Therefore, the present study aims to underline the importance of a critical and aware intervention plan for the conservation and damage prevention of cultural heritage, considering the possible support of HBIM tools.
\end{abstract}

Keywords: castles, ruins, cultural heritage preservation, architectural survey, archival research, in situ investigations

\section{Introduction}

The continuous loss or damage of monuments observed worldwide is caused by several reasons, both natural and man-induced. Among the natural phenomena, the occurrence of ground movements (landslides, subsidence) and seismic activity (earthquakes) are the most common causes. In general slow landslides are extremely sensitive to climate changes: extreme natural phenomena increase the effects of deformation and degradation processes. Then, seismic actions ultimately affect the stability of the architectural heritage. The consequences of these effects, combined with the insufficient and decreasing budgets for the conservation of monuments, are proving to be catastrophic for the Italian Cultural Heritage, as evidenced by the effects of the recent earthquakes (2012 in the Po valley and $2016 / 17$ in Central Italy). In this scenario, authorities in charge of preserving cultural heritage have a strong need for systematic, effective, usable and affordable tools and services to forecast and monitor degradation processes and to enable preventive maintenance.

In this perspective, in 2018 , with the aim of defining tools for the prevention of seismic damage on cultural heritage, a research project was launched, within the collaboration between the University of Parma and the Agency for Reconstruction of the Emilia Romagna Region. The research focuses on fortified architecture, which proved to be highly vulnerable to earthquakes, as shown by the damage that occurred after the 2012 Emilia seismic event. The study is analysing recurrent seismic damages and defining the seismic behaviour of these historic buildings, using the so-called phenomenological approach. This method relies on the observation and classification of the actual damage to recognize and classify recurring vulnerabilities (Coïsson, Ferretti \& Lenticchia, 2017).

In order to manage large numbers of buildings, this analysis is supported by the use of GIS (Geographic Information System), a tool that is becoming widespread in the field of architectural restoration (Bartolomucci, 2008). As a matter of fact, this software is a useful support for the management of conservation strategies on cultural heritage. It allows planning maintenance programs and preventive interventions, leading to more effective seismic improvements and reducing emergency interventions, which so far has guided the restoration works on the architectural heritage in response to

•Corresponding Author: Lia Ferrari, lia.ferrari@unipr.it 
earthquakes. Moreover, for a better distribution of the limited resources available, the definition of a priority list based on damage mechanisms rather than entire buildings (Cattari et al., 2014; Bartolomucci, 2012), as usually happens, would allow focusing the intervention on the most vulnerable elements. As a result, more buildings can be retrofitted. With this aim, further development of the aforementioned research would be the elaboration of experimental vulnerability curves. In this way, a low-cost tool is provided for the identification of vulnerabilities, in relation to the features of the building and local seismicity.

This kind of approach is fundamental for the preservation of fortified architecture, a peculiar typology that is widespread not only in Italy but also all over Europe. For centuries, fortresses have been a landmark, as well as an identifying symbol for communities. Starting from the encastellation phenomenon, this structure spread widely during the Middle Ages. Since then, the fortified structures have undergone several modifications and adaptations, but they have always remained important elements of the landscape and of the people's cultural identity.

An impressive system of castles, dating back to the $11^{\text {th }}$ century, characterises the area of Reggio Emilia (Fig. 1), in the Emilia Romagna Region (Manenti Valli, 1987). Among these fortifications, Canossa Castle is an important and distinctive fortress. Built on the top of an isolated cliff, a particularly strategic and defensive point, it played a central role in medieval European history. The Countess Matilde of Canossa placed there the political and military centre of a feud that extended from Lombardy to Tuscany.



Figure 1: Canossa Fortress is located on the hills of the province of Reggio Emilia, in northern Italy.

\section{Canossa: from fortress to ruin}

The first evidence of a fortified system on the top of Canossa cliff dates back to the beginning of the $10^{\text {th }}$ century (Manenti Valli, 2002). This historical period was characterised by political and social instability due to internal conflicts and barbaric invasions. For this reason, the Bishop of Reggio built a defensive system to protect the local community. Later, considering the strategic importance of the area, the first Count of Canossa, Atto Adalberto (939 - 988 A.D.) decided to improve the existent fortified system with the construction of an imposing fortress. Thus, Canossa Castle, whose construction period is uncertain, probably stood on the bishop's original establishment (Settia, 2015). Under the rule of Canossa Family (Atto 939 - Matilde 1115) the castle has undergone several modifications and adaptations, from the improvement of the defensive configuration to the transformation into a magnificent fortified palace. The Castle became one of the safest places in Europe, giving protection to important historical figures and playing a relevant role in European medieval history (Franceschi,1999; Piccinini \& Raffaelli, 2010). In the specific, in 1077, during the reign of Matilde, the castle became the set of a relevant episode in European history, the so-called "Walk to Canossa", which lead to the reconciliation between Emperor Henry IV and Pope Gregory VII, ending the Investiture Controversy thanks to the mediation of the countess (Bedogni \& Grasselli, 2007; Bedogni \& Grasselli, 2010).

After the end of Canossa's reign, the fortress and its surrounding changed owner several times and suffered relevant damages due to local conflicts. Various parts of the Castle were thus restructured or re-built. The last important conflict dates back to 1557, when Ottavio Farnese, Duke of Parma, attacked Ercole II, Duke of Ferrara and owner of the castle (Fig. 2). The conflict between the two families severely damaged the fortress (Grignano, 2006). In the following years, the castle was thus restored and its defensive system improved.

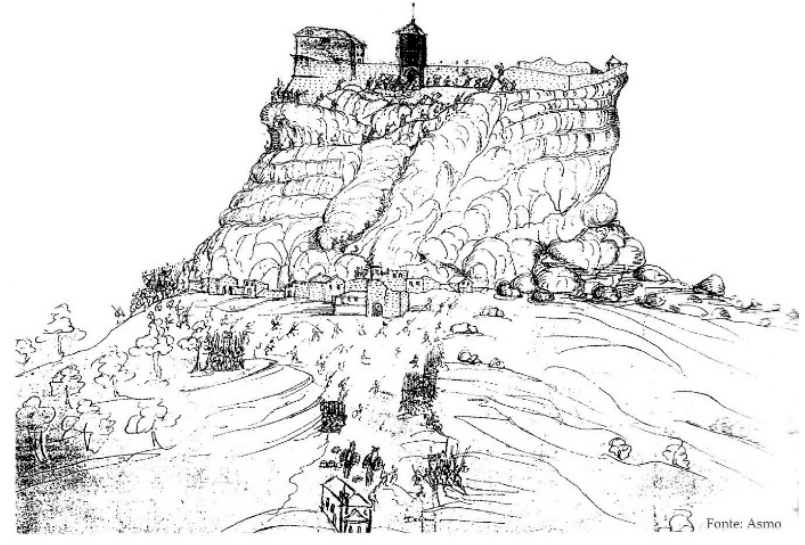

Figure 2: Illustration of the siege of Canossa Fortress during the attack moved by Ottavio Farnese to the Duke of Ferrara (1557), ASMO, Fund "Città", folder 142/3.

Then, Count Bonifazio Ruggieri definitely modified the defensive structure into a noble residence. In 1642, Francesco I, Duke of Modena, designed the knight Paolo Valentini as the owner of Canossa. From the beginning of the $19^{\text {th }}$ century, the fortress has fallen into a state of neglect, probably due to the dispossess made by the Napoleonic Edit.

The Castle remained the property of Valentini Family until 1881, the year in which the Italian State decided to purchase the monument. The negotiation between the previous owner and the State, represented by the palaeologist Don Gaetano Chierici (1819-1886), lasted several years.

In this period, the archaeological site (Fig. 3) was investigated through several excavation campaigns, directed by Chierici himself. During the first campaign (1877-1879) large quantities of debris (rubbles and earth) was removed, bringing to light the crypt and the adjacent rooms. Further excavation campaigns were carried out until 1892, discovering artefacts that helped to better understand the history of the monument (Spagni \& Ferrari, 1877;Campanini \& Ghirandini, 1984; Patroncini, 1997) Patroncini, 1997). In the first decade of the $20^{\text {th }}$ 
century, the archaeological site needed first aid interventions to secure the excavated areas and to allow access to the public: the monument became a national museum.

The two World Wars interrupted the restoration, resumed in the second half of the $20^{\text {th }}$ century. Between the 1960 s and 1980 s, new interventions concerned the stability of the cliff, affected by landslide. In the past 40 years, several invasive interventions have tried to strengthen the structure, deeply modifying the nature of the monument (Fig. 4).

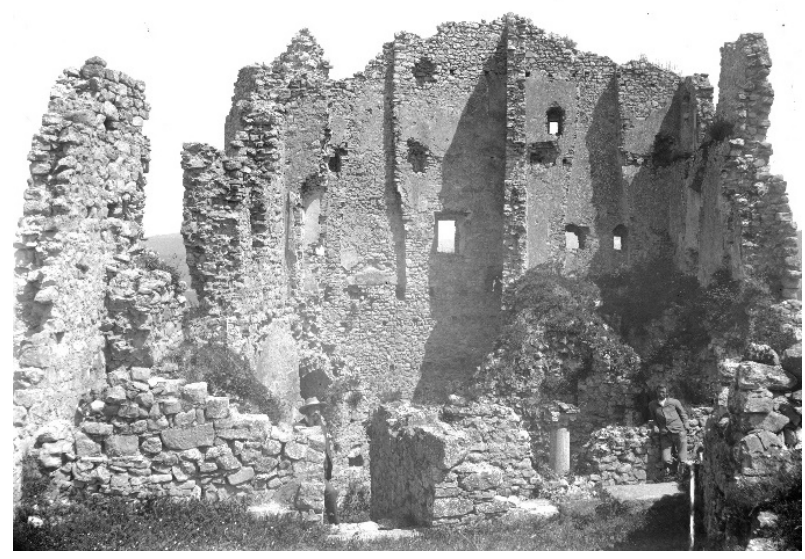

Figure 3: Picture of the second half of the $19^{\text {th }}$ century, representing the ruins of the Fortress before the interventions of the $20^{\text {th }}$ century.



Figure 4: The ruins of Fortress today after the interventions of the last 40 years.

The current state of ruins is therefore the result of damaging conflicts (from the $12^{\text {th }}$ to $16^{\text {th }}$ century), abandonment (18 ${ }^{\text {th }}$ century) and recent incongruent interventions $\left(20^{\text {th }}\right.$ century). Moreover, the harsh environment and seismic events caused the collapse of most of the structures. Archival research, in-situ inspections and photogrammetric techniques were carried out on Canossa Castle, in order to analyse the current state of conservation and underline the importance of a critical and aware intervention plan for the conservation and the prevention of damage of this important fortified system.

\section{Interventions: the fortress in the last $\mathbf{4 0}$ years}

The study presented in this paper focuses on the strengthening interventions carried out on the fortress in the last 40 years, of which we have evidence from archival research (Ministero per i Beni e le Attività culturali, 2019a; Ministero per i Beni e le attività Culturali, 2019b). The historical documentation allows identifying the main reinforcement interventions even if some inaccuracies prevent a complete and precise definition of the complex intervention system developed over the last decades. The documentation relating to the interventions carried out in the 1980s, in fact, is rather generic, not very technical and sometimes lacking graphics and detailed descriptions. Consequently, it was difficult to identify the accurate area of intervention, as well as to find information on the materials and techniques used in the restoration yards. Moreover, the terminology adopted in the archival documents is different from the current technical vocabulary, giving rise to misunderstandings. For instance, the term "mortar grout injections" is often used to refer to the technique of injected reinforcing bars. The reports of the interventions carried out in the 1990s are instead more complete and detailed. However, even in this case, information regarding the localisation of interventions, is usually not accurate. Graphic drawings, when available, simplify the castle shapes with regular geometries. Furthermore, the proportions are often not respected, making it even more difficult to identify the precise areas of intervention (Fig. 5).



Figure 5: On the right, graphic representation of the position of the reinforcing bars on the northern front (intervention carried out in 1979). This reconstruction is made difficult by the evident simplification of geometries in the drawings of the archive documentation, on the left.

The first interventions analysed date back to the years 1979-1980. In this phase, foundation micro-piles were installed in correspondence with the eastern elevation. Other interventions were carried out to strengthen the masonry walls which were in a precarious state of conservation, because of the presence of vegetation. The documents refer to the insertion of reinforcing bars into the wall thickness, in order to reconnect the external layers with the central core. In-situ investigations show that these cement mortar injections concerned all three 
elevations. Overall, this strengthening intervention is rather invasive and ill-conceived: in the following years, cement mortars, in contact with humidity, created efflorescence, which caused the detachment of the surface layers, worsening the degradation of the original materials. Moreover, the anchorages were hidden under masonry, requiring the demolition of a portion of the original material. The metal plates were sometimes covered with a salvaged stone, other times with stones similar to the original ones, making it difficult to recognise their authenticity. Moreover, the frequency of installation of these elements suggests a complete renewal of the east and south façade and part of the north façade, losing its original image and its historicity.

The following consolidation project, dating back to 1983, shows an improvement in the level of knowledge of the architectural organism. The operations are more targeted and calibrated according to the area under investigation. In this phase of intervention, a water drainage system was created and a so-called "crodolo" (ring beam) were installed in correspondence with the two horizontal floors. Thanks to the in-situ investigation (presented in paragraph 4) it has been possible to understand that the term actually refers to metal tie-rods. The purpose of the two-level tie-rods system was to avoid dangerous overturning mechanisms, restoring the box-like behaviour of the structure. Furthermore, the base of the most vulnerable fronts, the southern and the eastern one, has been strengthened again through the insertions of reinforcing bars. As will be explained in paragraph 4, the in-situ investigation has shown that this additional system of reinforcing bars integrates, without overlapping, the one created in the previous interventions (1979-1980).

In 1985, the consolidation and restoration of the crypt began. The interventions concerned the central portion of the walls, which goes from the entrance vault on the north side to the access to the adjacent rooms on the south side. In the same year, the Ceramic Center of Bologna carried out chemical analysis on the reinforced masonries. The purpose was to identify the state of conservation of the materials. The analysis showed the presence of degradation in the masonry walls due to different factors. First of all, it has been highlighted an excessive accumulation of water inside the walls: the excessive exposure to atmospheric agents favoured the penetration of water inside the masonry, whereas the binders used for the finishes and the cement-based injections prevented its evaporation. In addition, the presence of ettringitis was also detected: the formation of this dangerous salt has been increased by the reaction between the injected cement and the lime sulphates, present in large quantities. Ettringitis, by increasing its volume, creates compressive stresses inside the masonry layers, causing swelling, fractures and detachment phenomena. The previous injections of cement mortars (1979-1980), of which the monument is studded, have thus contributed to worsening the crack pattern, showing fractures even in recently restored parts and in areas previously unrelated to crack phenomena. Therefore, this study has been essential to understanding the ineffectiveness and the inadequacy of the interventions performed until then. In 1986, once the results of the chemical tests were obtained, the restoration yard was immediately interrupted.
The following years, other interventions for restoring portions of degraded masonry started over. These parts were demolished and rebuilt with salvage stones or new ones, according to the availability. Once again, mixture of hydraulic lime and cement type 425 were used, even if the results of the chemical analyses have advised against the use of such type of binder. The same approach was used for the local dismantling and reconstructions that concerned the south-east corner in 1987. Consequently, a few years later, in 1988, the detachment between masonry layers seriously worsened, giving rise to a widespread crack pattern. The intervention carried out to repair this situation replaced the original stone material of the masonry core, completely disregarding the preservation of the original features of the monument.

It is therefore possible to note that, at least until the 1990s, the interventions did not conform to the principles of restoration (reversibility, recognisability, minimum intervention). The strengthening techniques have been carried out with unsuitable materials (e.g. cement-based mortars) which, in some cases, worsened the situation, giving rise to new crack patterns and degradation of the material.

In 1991 interventions focused mainly on the northern front and on the crypt, with rather invasive procedures. In particular, the upper part of the front undergone demolition and reconstruction operations within the wall thickness, in order to reinforce the masonry faces. The interventions in the crypt were aimed at removing the cement mortars trying to remedy the incongruent past consolidations. Although the purpose was good, the adoption of sandblasting to remove the mortar joints has erased the historical patina, that characterised the original stones. This aggressive technique not only brought the monument to a state of conservation that perhaps it had never had before, but also it has weakened the masonry.

Hence, these latest interventions still denote insufficient awareness and lack of respect for the historical construction (e.g. sandblasting), even if the previous reports and studies have provided a deeper knowledge of the monument. Furthermore, looking at the historical background in which these interventions took places, guidelines already existed, that suggested the principles for a respectful and conscious restoration, aimed at transferring the cultural and historical value of the monument to future generations (Brandi, 1977). The importance of the so-called "path of knowledge", the preservation of building historicity and the compatibility between reinforcing materials and existing structures was already recognized as fundamental.

It was only in the early 2000 s that interventions began to be more aware of the preservation issues of the architectural heritage. In 2005, fourteen tie rods were installed on the southern front of the fortress. In the meantime the techniques have improved becoming less invasive: the tie rods were made of steel strands with a diameter of $15 \mathrm{~mm}$ and required small holes to be placed. These holes were drilled by rotation, without hammering effects in order to avoid damaging the walls. Actually, this new intervention has concerned a portion of the fortress, which was already undergone a similar strengthening. Indeed, this tie-rods system implemented the previous one, inserted a few decades earlier (1983). This may be a sign both of the worsening of the structural condition of the castle and of the loss of effectiveness of the existent 
tie-rods, perhaps due to chemical reactions between the cement mortars and the humidity in the masonry (Fig. 6).

Today, it is difficult to distinguish the different interventions and the original historical material from the new products used in the interventions described above. These strengthening operations, even if aimed at the conservation and protection of the monument, proved to be invasive, ineffective and sometimes harmful. Furthermore, the archival documentation shows that many of the consolidation interventions seem to overlap with others strengthening tools previously inserted in the same area. Further analysis is therefore required to investigate the correspondence between the historical documentation and the actual state of the monument in order to verify whether all the aforementioned interventions have been realized. For this reason, in-situ investigations were carried out to identify the presence of past interventions, their extension and the actual technique.



Figure 6: Graphic representation of the strengthening interventions carried out on the southern front: tie rods placed in 1983 (yellow) and in 2005 (green) are in a similar position. It may be a symptom of the inefficiency of the first intervention.

\section{Instrumental analyses}

Some interventions, mentioned in the archive reports, appear difficult to identify both in terms of consolidation technique and in terms of extension, which sometimes seems unreliable. Indeed, in the reports and in the metric computation, some interventions are described with technical terminology that, today, has a completely different meaning compared to the one attributed in the historical period of the reports. As a consequence, also in consideration of the operative practices of the period (last 20 years of $20^{\text {th }}$ century), it is assumed that the description presented in the archival documents could not completely fit with the actual interventions carried out on the fortress.

However, another reason may explain the overlapping of several chronologically successive interventions in the same portion of the monument. For instance, this overlapping could be due to representation inaccuracies. The manual drawing, indeed, required a very long time for the elaboration of the projects, especially in buildings characterized by a high level of complexity, such as Canossa Castle. It could happen that the few tables representing the monument, belonging to previous projects, have been used to indicate the new interventions, even if placed at a different level than the one represented. In the case of Canossa fortress, drawings belonging to different reports present the same graphic representations in plan, sections and elevations. These similarities have therefore suggested the abovementioned approach, which implies inaccuracies in the location of the intervention areas. In addition, there is a possibility that past interventions were not considered during the most recent design phases. However, in this case, the existence of a past intervention should have emerged during the construction phase, leading to three possible choices:

1. the removal and replacement of the previous intervention with the new one;

2. the reassessment of the design choices (not always supported by documents), with consequent relocation of the new consolidation elements, if the existing intervention was deemed not sufficient to ensure the stability of the structure;

3 . renunciation of carrying out the new intervention.

In light of these considerations, the direct investigation of the monument is fundamental to better understand the interventions realized in the past in order to identify the actual vulnerabilities, still present. The monument was thus investigated with in-situ inspections, both visual and instrumental.

First of all, this analysis were aimed at identifying the interventions carried out around the 1980s which, more than others, generated the serious cracking pattern that still affects the fortress today. In 1985, indeed, chemical analysis showed that these interventions, made with cement mortars (incompatible with the historic masonry of the fortress), were one of the main causes of the crack pattern that occurred on the monument in the periods immediately following their fitting.

Through the use of specific instrumentation (metal detector Bosch DMF 10 ZOOM Professional and concrete rebar scanner Hilti Ferroscan rv 10) the presence of iron elements under the surface of the masonry was investigated in the areas where the reports of 1979 and 1983 indicated the presence of "grout injections". Indeed, despite the terminology, the description of the interventions suggested the presence of reinforcing bars. The aim was to assess the actual presence of the reinforcing bars injected into the masonry, their extension and the possible overlapping of the consolidations described in both the reports (1979 and 1983). The scans carried out with Ferroscan (rebar scanner) were limited to two precise points of the castle, both in the crypt, in order to verify two elements placed in 1983. A grid with dimensions of $80 \times 80 \mathrm{~cm}$, divided into 4 horizontal and 
vertical bands of $20 \mathrm{~cm}$ each, was used for scanning. Once the grid was positioned on the chosen surface, the scan was performed from left to right, starting from the upper band and continuing with the same methodology in the bands below. The same procedure is then repeated, but scanning the bands from top to bottom. The data collected has been processed with the software provided by the manufacturer (Hilti ferroscan v4.0), in order to obtain more information about the characteristics, location, depth and shape of the elements investigated. The largest number of reinforcing bars were found on the eastern front. Moreover, the inspection showed the presence of two distinct systems of reinforcing bars that intersect without overlapping (Fig. 7).

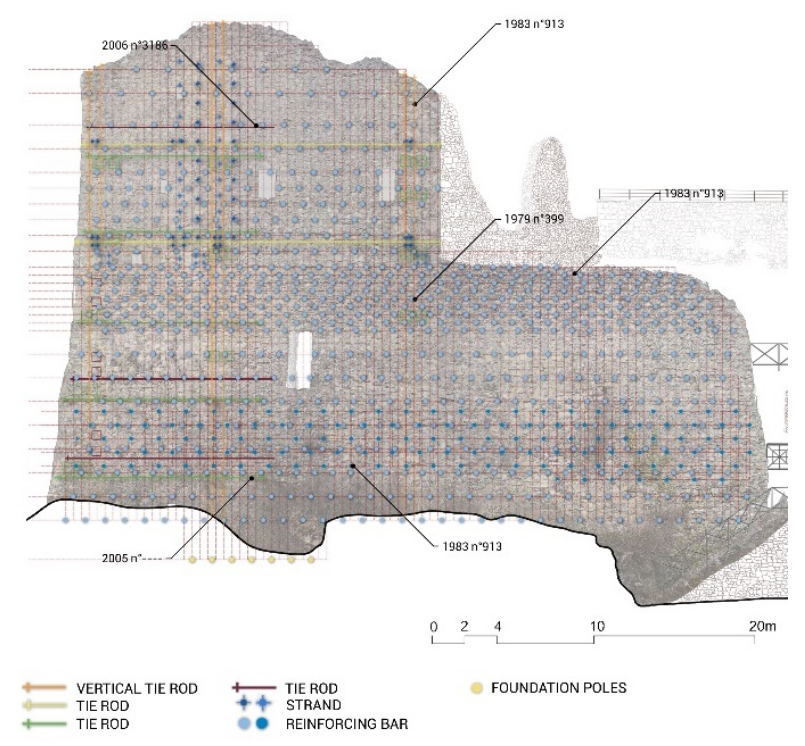

Figure 7: Graphic representation of the strengthening interventions carried out on the eastern front: it is possible to identify two distinct texture that intersects without overlapping: the reinforcing bars placed in 1979 (blue) and 1983 (light blue).

With these data it is possible to define the reliability of the aforementioned reports, whose interventions with the reinforcing bars have actually been placed not overlapped, but with a slight translation of the two reinforcing bars systems.

Similar investigations were performed to analyse another intervention mentioned in the 1983 report, which indicated the construction of ring beams ("cordoli" is the Italian word in the report), inside the masonry, arranged on several levels connecting the eastern front with the thick walls of the crypt in order to create a "frame". Therefore, the additional part at the top of the fronts of the monument and the perimeter walls of the crypt were investigated. The analysis performed with the metal detector initially highlighted the presence of a metal element, which was then further investigated through the use of Ferroscan. However, the investigations have excluded the presence of a beam, showing instead the presence of a circular anchor plate with reinforcing stiffeners, inside the masonry (Fig. 8).

From this, it can be deduced that the intervention of 1983 consisted of the insertion of tie rods. Probably the term "cordolo" was used improperly to indicate the frame made once the tied-rods system was installed. As can be seen from the image, the elements that make up the extreme portion of the tie rod are rather eroded, probably due to a large amount of moisture present inside its walls.

\section{Photogrammetric survey: geometric and environmental complexity}

The survey of the Canossa Castle was a fundamental support for the analysis of the aforementioned interventions. Nevertheless, several difficulties emerged during the survey campaign, mainly, due to the geometrical complexity and morphological irregularity of the object (Fig. 9), as well as to the difference in height of the cliff peak.

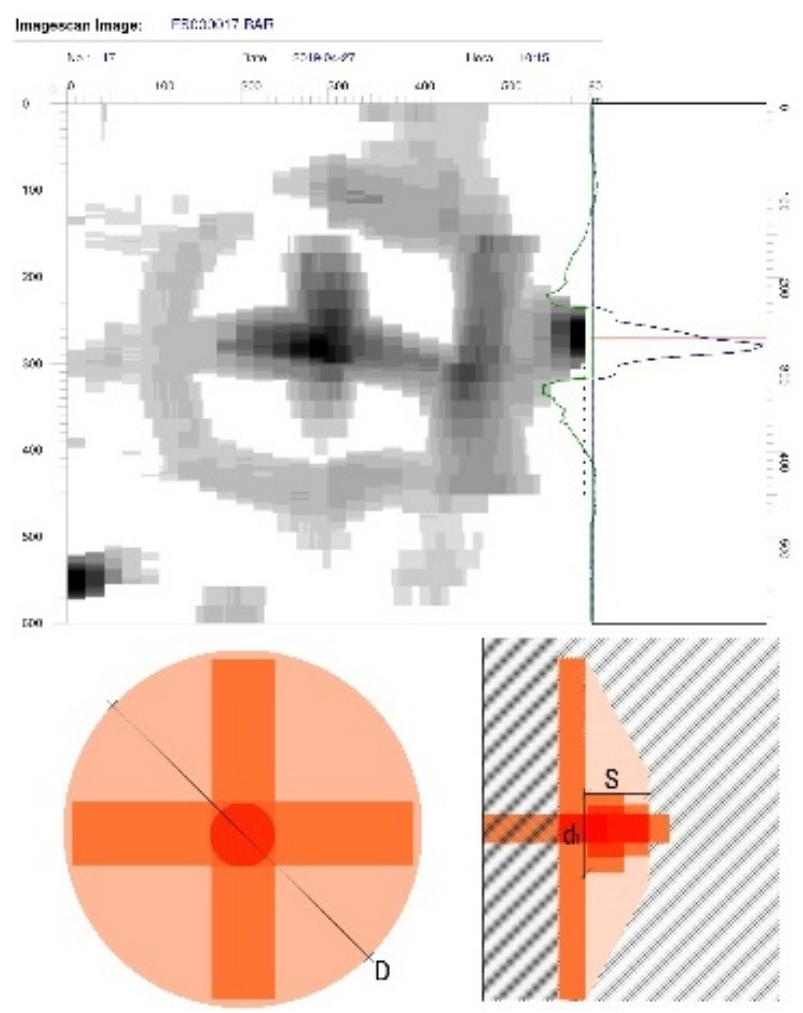

Figure 8: Scan with rebar detector of an anchor plate inside the masonry and graphical representation.

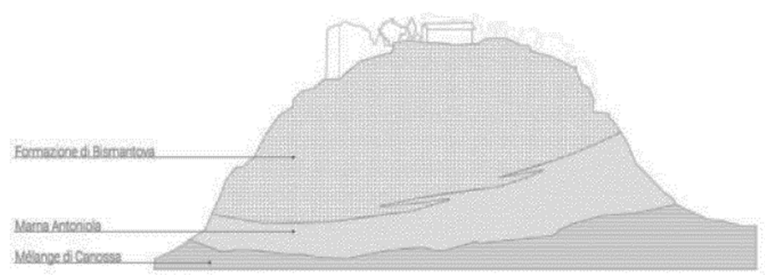

Figure 9: The complex orography of the area, not only caused part of the crack pattern of the fortress, but also made it difficult to survey the external façades.

To overcome these difficulties, different survey techniques were used (Pane et al, 2020). With the collaboration of the University of Cesena, a survey was first carried out with the aid of laser scanner technology. The instrument was located at several points to scan the main portions of the ruins and specific archaeological artefacts. However, the morphology of the cliff and the tight spaces of the ruins made it impossible to reach all surfaces of the monument using the instrument with a tripod. The final result, a dense point cloud, was thus 
incomplete of most of the external surfaces, located on the cliff edge. For the purpose of this study, a complete model of all surfaces of the monument was required.

Therefore, in order to survey all the surfaces arranged along the ridge, it was decided to carry out a photogrammetric survey performed by a drone. The photogrammetric model (Fig. 10) of the external façade was scaled thanks to the common part available in both point clouds (the laser scanner point cloud and the photogrammetric one). Furthermore the geo-localization of the two models made the interpolation between the two clouds possible.

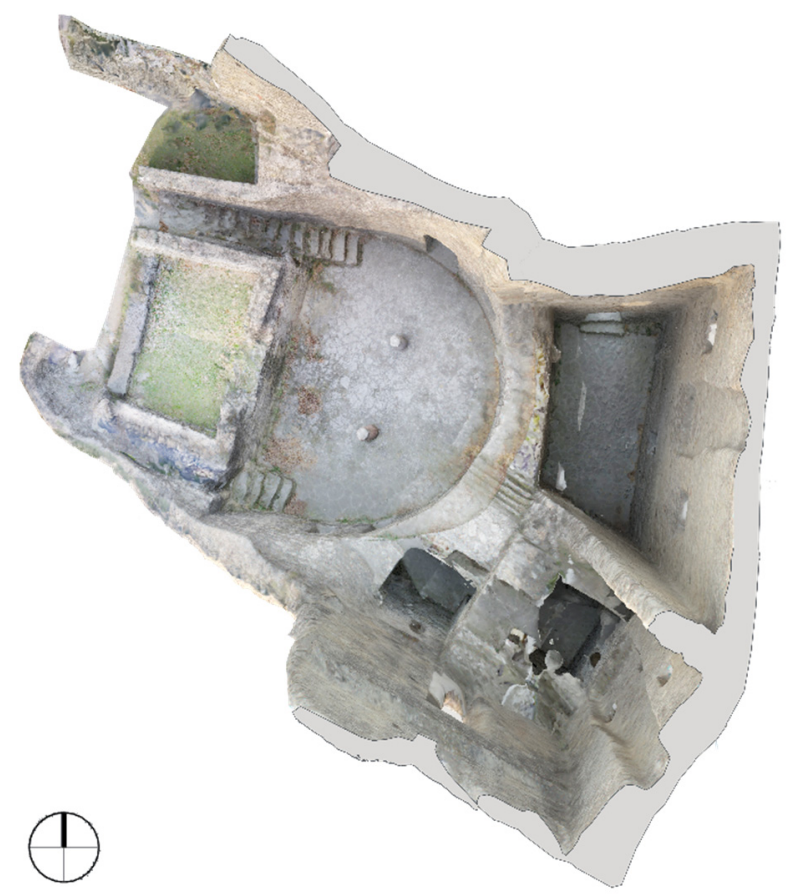

Figure 10: Top view of the fortress obtained from the photogrammetric model.

The point cloud obtained from this interpolation was uploaded into the BIM software (Building Information Modelling), in order to create an accurate parametric approximation of the monument in which to insert the data on the materials and the interventions realized during the $20^{\text {th }}$ century on the fortress. The aim was to ensure a global overview of the previous works and to point out the area where possible structural problems could arise because of both excess and lack of strengthening. Unfortunately, once again, the geometric complexity of the ground and ruins, as well as the irregularities in thickness and in height of the masonry walls, have caused difficulties in using the BIM software (Archicad and Revit). Specifically, the main problems in the use of Revit concerned the approximation of geometries and the nonintuitive insertion of elements placed at different heights from predetermined levels and not orthogonal to the model. The model and its elements were easier to manage in Archicad, even for non-experts users, but, on the other hand, the accuracy remains unsatisfying.

Therefore, the BIM models thus obtained were inaccurate in several respects due to the lack of flexibility of the BIM towards particular construction types, characterized by significant geometrical irregularities. It was therefore preferred to proceed with the use of the photogrammetric survey, which allowed us to achieve a much more precise result. Photogrammetric software, Agisoft PhotoScan (Agisoft Metashape, 2020), and CAD software made it possible to recreate accurate plans, sections and all the façades of the monument by freely choosing the cutting plans of the point cloud. However, the photogrammetric model does not have the same potential as the BIM one: the choice of these tools reduced the global vision of the monument and the possibility of an immediate consideration and perception of all the works realized on the monument.

To solve this problem, the solid mesh of the monument could be imported into a modelling program. This possible solution allows to have a global view of the monument and the possibility to insert all the restoration and strengthening interventions carried out during the last century, but without the possibility provided by BIM software.

\section{Conclusion}

The research on the case study of Canossa Castle has shown that the recent interventions carried out on the fortress have slowly transfigured the image of the monument we see today. Some of these interventions, disregarding the principles of restoration, have used incompatible materials that have compromised the historicity and the appearance of the fortress. Several reinforcing interventions have also proved to be ineffective leading to the need to strengthen the same part several times, thus becoming excessive and invasive. In general, most of the restorations carried out in the last decades of the $20^{\text {th }}$ century, lacking a historical analysis and a deep knowledge of the building, have generated dangerous effects for the conservation of the monument.

Furthermore the archival documentation relating to these interventions is inaccurate and lacking in information, preventing the understanding of the current state of the monument from being achieved. In-situ investigation for defining the actual strengthening techniques used in past intervention and their localisation were therefore required to define a clear picture of the architectural object to be conserved.

To this aim, significance, knowledge, conservation and management should be brought together, considering many aspects: historical data, philological approach, degradation mapping, structural analysis, multidisciplinary modelling, conservation plan guidelines, code checking, structural health monitoring.

In this regard, the use of BIM models would make it possible to organise all the information collected on Canossa Castle, laying the basis for any future conservation activities on this archaeological site. In particular, these tools could prove to be very useful as a database of past interventions and to plan future ones, in order to define a long-term maintenance program of the asset. This strategy could have positive results not only from an economic point of view, but also (and even more important) from the point of view of conservation, avoiding unnecessary interventions and respecting the value of the cultural heritage.

However, in this case, the difficulties in processing complex geometries with BIM software (Revit and Archicad) prevented the elaboration of a parametric 
model by non-expert users. Instead, CAD software (Autocad 3D) combined with photogrammetric software (PhotoScan), proved to be a more flexible tool, allowing a wider range of users to describe complex and irregular morphologies, typical of ruins. However, the mesh developed with this type of software cannot become an information or monitoring database as the BIM model.

Nonetheless, photogrammetric software is increasingly developing becoming more and more automated, accurate and easy to use, helping even non expert-users to survey complex buildings such as fortified architecture. On the other hand, the risk is to generate an overproduction of data, difficult to manage and actually useless for the survey, the interventions and, in general, the conservation plan.
It is therefore important to underline that, despite the growing automation of this software, the architect should continue to play the main role in the preservation process because of its competence to produce a survey that is not only correct but also the result of a critical interpretation of data (Fallavollita \& Ugolini, 2017). This critical analysis is even more important in the case of the survey of archaeological ruins, whose geometries are anything but regular and easy to interpret and where the edge between architecture and rubbles is often blurred (Ugolini, 2010). Moreover, the survey of these ruined monuments assumes considerable documentary importance in those ruins whose decline we are called to slow down as much as possible but which may ultimately be unavoidable.

\section{References}

Agisoft Metashape, (2020). User Manual Professional Edition, Version 1.6. Retrieved November 25, 2020, from https://www.agisoft.com/downloads/user-manuals/

Bartolomucci, C. (2008). I GIS per la conservazione dell'architettura storica. MondoGIS 66/67, 13-17 (ISSN 1128-8175).

Bartolomucci, C. (2012). II terremoto sui beni archeologici: una casistica dei danni. II patrimonio culturale dopo il terremoto del 6 aprile del 2009. Siti archeologici nell'Aquilano, 385-389.

Bedogni, B. J., \& Grasselli, G. (2007). Matilde di Canossa: Una regina cento castelli. Montecchio Emilia (RE), Cipsa Soc. Coop. Sociale.

Bedogni, B. J., \& Grasselli, G. (2010). Matilde di Canossa: la storia in immagini. CIPSA. Montecchio Emilia.

Brandi, C. (1977). Teoria del Restauro. Einaudi Editore.Torino.

Campanini, N., \& Ghirandini, L. (Eds) (1984). Canossa guida storico illustrata. Editrice Bizzocchi. Reggio Emilia.

Cattari, S., Degli Abbati, S., Ferretti, D., Lagomarsino, S., Ottonelli, D., \& Tralli, A. (2014). Damage assessment of fortresses after the 2012 Emilia earthquake (Italy). Bulletin of earthquake engineering, 12(5), $2333-2365$. https://doi.org/10.1007/s10518-013-9520-x

Coïsson, E., Ferretti, D., \& Lenticchia, E. (2017). Analysis of damage mechanisms suffered by Italian fortified buildings hit by earthquakes in the last 40 years. Bulletin of Earthquake Engineering, 15, 5139-5166. https://doi.org/10.1007/s10518-017-0172-0

Fallavollita, F., \& Ugolini, A. (2017). New methodologies for the documentation of fortified architecture in the state of ruins. Int. Arch. Photogramm. Remote Sens. Spatial Inf. Sci., XLII-5/W1, 411-418. https://doi.org/10.5194/isprs-archivesXLII-5-W1-411-2017

Franceschi, E. (Eds.) (1999). Castelli reggiani: castelli rocche fortilizi feudi feudatari del territorio reggiano. Finale Emilia.

Grignano, M. (2006). L'incastellamento matildico nell'Appenino Reggiano. Ricerche storiche e analisi della stratigrafia muraria. Degree course in Archaeology and Conservation of Archaeological Heritage, University Cà Foscari of Venice. Tutor Gelichi S., Co -Tutor Librenti M.

Manenti Valli, F. (1987). Architettura di castelli nell'appennino reggiano. Edizioni Aedes Muratoriana.

Manenti Valli, F.(Eds.) (2002). Architettura fortificata un problema interpretativo e operativo il sistema castellano matildico: atti del convegno nazionale degli studi castellogici. Istituto italiano dei castelli, Roma.

Ministero per i Beni e le Attività Culturali (2019a). Soprintendenza Archeologia, Belle Arti e Paesaggio per la città metropolitana di Bologna e le province di Modena, Ferrara e Reggio Emilia. Reports $n^{\circ} 399$ of 1979; $n^{\circ} 913$ of 1983; $n^{\circ} 1437$ of $1988 ; n^{\circ} 1873$ of $1991 ; n^{\circ} 3165$ of 2005; $n^{\circ} 3186$ of 2006. Retrieved November 25, 2020, from http://www.sbapbo.beniculturali.it/

Ministero per i Beni e le Attività Culturali (2019b). Soprintendenza Archeologia, Belle Arti e Paesaggio per la città metropolitana di Bologna e le province di Modena, Ferrara e Reggio Emilia. Cronologia di Canossa. Folder 01; REM_5 (1982/1905). Retrieved November 25, 2020, from http://www.sbapbo.beniculturali.it/

Pane, A., Catuogno, R., Facchini, M., \& Morano, L. (2020). A Fortress Between Artifice and Nature: the Laser Scanning Survey of the Castle of Pescopagano as AN Instrument of Knowledge, Conservation and Enhancement. Int. Arch. Photogramm. Remote Sens. Spatial Inf. Sci., XLIV-M-1-2020, 405-412. https://doi.org/10.5194/isprs-archives-XLIVM-1-2020-405-2020

Patroncini, L. (1997). Canossa: ricerche sulla struttura castrense. Quaderni d'Archeologia Reggiana. Edizioni Italgraf. 
Piccinini, D., \& Raffaelli, F. (2010). Castelli, dimore storiche e rocche dell'Emilia Romagna. Alberto Perdisa Editore

Settia, A. (2015). Canossa: Segno di Simbolo e Storia: atti e memorie del V convegno di studi Matildici. Deputazione di storia e Patria per le antiche province modenesi, Sezione di Reggio Emilia. Aedes Muratoriana. Modena.

Spagni, E., \& Ferrari, G. (1877). Relazione delle gite fatte a Canossa dai soci del Club Alpino. Sezione dell'Enza nei giorni 31 maggio e 10 giugno 1877 e proposta scavi. Editore Calderini. Reggio Emilia.

Ugolini, A. (Eds.) (2010). Ricomporre la rovina. Alinea Editrice 